CLINICAL STUDY

\title{
Acute estrogen exposure does not affect basal very low-density lipoprotein-triglyceride production or oxidation in postmenopausal women
}

\author{
Lars C Gormsen $^{1,2}$, Christian Høst ${ }^{1}$, Britta Eilersen Hjerrild ${ }^{1}$, Claus H Gravholt ${ }^{1}$ and Søren Nielsen ${ }^{1}$ \\ ${ }^{1}$ Medical Department M (Endocrinology and Diabetes), Aarhus University Hospital, DK-8000 Aarhus, Denmark and ${ }^{2}$ Department of Nuclear Medicine, \\ Aarhus University Hospital, Skejby, DK-8200 Aarhus N, Denmark
}

(Correspondence should be addressed to L C Gormsen; Email: lars.christian.gormsen@ki.au.dk)

\begin{abstract}
Context: Long-term hormone replacement therapy (HRT) with estradiol $\left(\mathrm{E}_{2}\right)$ is associated with an altered lipid profile including unfavorable increases in triglyceride (TG) concentrations and augmented hepatic very low-density lipoprotein (VLDL)-TG production. There are indications that this effect of estrogens may be immediate.

Objective: To study the in vivo effect of a single dose of $\mathrm{E}_{2}$ on VLDL-TG kinetics and oxidation in humans. Methods: Eight healthy, postmenopausal women were given a single dose of either placebo or $\mathrm{E}_{2}(4 \mathrm{mg})$ orally. VLDL-TG kinetics was assessed by a 240-min primed-continuous infusion of ex vivo labeled $\left[1-{ }^{14} \mathrm{C}\right]$ triolein-labeled VLDL. Fractional and absolute VLDL-TG oxidation was determined by hyamin trapping of exhaled ${ }^{14} \mathrm{C}$ label. Indirect calorimetry provided measurements of lipid oxidation.

Results: Administration of $4 \mathrm{mg}$ of $\mathrm{E}_{2}$ orally rapidly increased plasma $\mathrm{E}_{2}$ concentrations from below detection threshold to premenopausal levels. Free fatty acids (FFA) and TG concentrations were unaltered. No immediate effect was observed on either VLDL-TG production (placebo versus $\mathrm{E}_{2}$ ): $20.0 \pm 12.4$ vs $24.1 \pm 10.7 \mu \mathrm{mol} / \mathrm{min}, \quad P=0.33$; VLDL-TG oxidation: $12.3 \pm 10.9$ vs 12.6 $\pm 5.6 \mu \mathrm{mol} / \mathrm{min}, P=0.93)$; or VLDL-TG clearance rates: $51.4 \pm 16.8$ vs $64.9 \pm 28.8 \mathrm{ml} / \mathrm{min}, P=0.34$ ). Conclusions: Short-term $\mathrm{E}_{2}$ elevation does not affect VLDL-TG production, oxidation, or clearance in humans. We therefore propose that HRT-associated dyslipidemia has a gradual rather than immediate onset.
\end{abstract}

European Journal of Endocrinology $163421-426$

\section{Introduction}

Postmenopausal hormone replacement therapy (HRT) is associated with favorable changes in lipid profile including lowered levels of low-density lipoprotein (LDL) and increased high-density lipoprotein (HDL) (1). Administration of estrogens, however, may cause hypertriglyceridemia, a non-favorable effect (2) on the individual's risk of developing cardiovascular disease. Increased concentrations of circulating triglycerides (TGs) may stem from either: i) increased hepatic production and secretion of TG rich very low-density lipoproteins (VLDLs), or ii) reduced peripheral clearance by lipoprotein lipase (LPL), hepatic lipase, direct catabolism, and/or LPL receptors (3). Whereas LPL activity is modified by estradiol $\left(\mathrm{E}_{2}\right)$ according to whether the enzyme is located in muscle or adipose tissue, there is now general agreement that long-term estrogen administration augments hepatic VLDL production (1) and leads to elevated TG levels.
Although it is certainly possible that the TG increasing effect of estrogens may develop gradually over weeks and months, there are indications that the effect may be more immediate. Animal studies indicate that the hypertriglyceridemic effect of estrogen may have an acute onset. Thus, cultured chick hepatocytes stimulated by estrogen for $3 \mathrm{~h}$ secrete significantly more VLDL particles than control hepatocytes (4). Moreover, both $A P O B$ mRNA and secretion of VLDL increase following a single injection of either diethylstilbestrol (5) or $E_{2}(6)$, an effect possibly mediated by the activation of membrane-bound estrogen receptors (ERs), enabling rapid cellular signaling (7). Thus, the effect of $\mathrm{E}_{2}$ on lipid metabolism and hence on body composition appears to be direct and mediated via ERs. These observations have led to renewed interest in adipocyte receptor subgroups, and recently, Dos Santos et al. (8) demonstrated the existence of a membrane-bound ER $\alpha$. In that study, the authors demonstrated that physiological concentrations of $E_{2}$ rapidly lead to activated $\mathrm{p} 42 / \mathrm{p} 44$ 
MAPK, and that this effect could be blocked by an estrogen antagonist. Furthermore, infusion of conjugated estrogens increases insulin action within hours, and decreases plasma glycerol concentrations during a hyperinsulinemic euglycemic clamp (9), rendering it plausible that a range of signaling cascades is activated acutely by $\mathrm{E}_{2}$.

No previous study has assessed whether $\mathrm{E}_{2}$ has an immediate effect on hepatic VLDL-TG production in humans; thus, we studied the effect of oral administration of $4 \mathrm{mg} \mathrm{E}_{2}$ on VLDL-TG kinetics and oxidation in postmenopausal women using ex vivo labeled $\left[1-{ }^{14} \mathrm{C}\right]$ triolein and the primed-constant isotope dilution technique (10).

\section{Materials and methods}

\section{Subjects}

The participants were eight healthy, postmenopausal women $(56 \pm 4$ years, $65 \pm 8 \mathrm{~kg}$ body weight, 24.2 $\pm 1.2 \mathrm{~kg} / \mathrm{m}^{2}$ body mass index, $40 \pm 4 \mathrm{~kg}$ lean body mass (LBM), $22 \pm 5 \mathrm{~kg}$ fat mass). None used HRT, and all had $\mathrm{E}_{2}$ levels below $0.07 \mathrm{nM}$. Informed consent as well as ethics committee approval was obtained from all participants prior to the study, which was conducted in accordance with the Declaration of Helsinki II. Volunteers were recruited from an ongoing study of the impact of $E_{2}$ on lipolysis. The study is in preparation for submission.

\section{Protocol}

The subjects were examined on 2 days separated by 1 month. On all examination days, the subjects received either placebo or $\mathrm{E}_{2}(4 \mathrm{mg})$ at $0600 \mathrm{~h}(t=-120 \mathrm{~min})$ after a 10-h overnight fast. Two i.v. catheters were inserted - one in an antecubital vein for infusion of the VLDL tracer and saline, and the other one in a dorsal vein on the contralateral hand. The latter was used for blood sampling. The hand was placed in a heated box in order to obtain arterialized blood. At $t=0 \mathrm{~min}$, a bolus followed by a constant infusion of VLDL tracer was administered. The VLDL infusion was maintained for $240 \mathrm{~min}$, and blood samples for determination of VLDLTG concentration, specific activity (SA), and metabolites were drawn at $t=180,210$, and $240 \mathrm{~min}$. Indirect calorimetry was performed for $30 \mathrm{~min}$ from $t=210 \mathrm{~min}$.

VLDL tracer preparation The procedure used to label the TG moiety of the VLDL particle ex vivo has been described previously in detail (11). In brief, 80-ml blood was drawn from each participant, plasma was separated by a short spin, $30 \mu \mathrm{Ci}\left[1-{ }^{14} \mathrm{C}\right]$ triolein (PerkinElmer, Inc., Turkku, Finland) dissolved in $300 \mu \mathrm{l}$ ethanol (Merck \& Co., Inc.) was added, and the solution was then sonicated at $37^{\circ} \mathrm{C}$ for $6 \mathrm{~h}$. Subsequently, labeled VLDL particles were separated from other particles in plasma by $18 \mathrm{~h}$ of ultracentrifugation at $98350 \boldsymbol{g}$ and $4{ }^{\circ} \mathrm{C}$. Samples were tested for bacterial growth to ensure sterility, and the solutions were stored at $4{ }^{\circ} \mathrm{C}$ until use $(<1$ week).

VLDL-TG concentration and SA VLDL particles were isolated from $\sim 3 \mathrm{ml}$ of each plasma sample by ultracentrifugation as described above. The supernatant containing the VLDL fraction was obtained by tube slicing (Beckman Instruments, Inc., Palo Alto, CA, USA). Then, $300 \mu \mathrm{l}$ were transferred to a scintillation vial, and ${ }^{14} \mathrm{C}$ activity was measured by dual-channel liquid scintillation counting to $<2 \%$ counting error (11).

Breath ${ }^{14} \mathrm{CO}_{2}-\mathrm{SA}$ Subjects expired into breath bags (IRIS-breath-bags; Wagner Analysen Technik, Bremen, Germany), and exhaled air passed through a solution containing benzethonium hydroxide (Sigma-Aldrich, Inc.) with thymolphthalein (Sigma-Aldrich, Inc.) in a scintillation vial. A color change (blue to clear) occurred when exactly $0.25 \mathrm{mmol} \mathrm{CO}_{2}$ was trapped in the solution. Scintillation fluid was added to the vial, and ${ }^{14} \mathrm{CO}_{2}$ activity was measured by liquid scintillation counting to $<2 \%$ counting error.

Indirect calorimetry $\mathrm{CO}_{2}$ flow and substrate oxidation rates (12) were measured by indirect calorimetry (Deltatrac monitor, Datex Instrumentarium, Helsinki, Finland). After $5 \mathrm{~min}$, adaptation to the hood $\mathrm{VCO}_{2}$ measurements was averaged from $t=185$ to $210 \mathrm{~min}$.

Calculations VLDL-TG production - primed-constant infusion:

VLDL production and clearance rates were calculated as described in detail previously (10):

$\operatorname{VLDL}-\mathrm{TG} \operatorname{Ra}(\mu \mathrm{mol} / \mathrm{min})=\frac{F}{\mathrm{SA}}$

VLDL-TG Clearance ( $\mathrm{ml} / \mathrm{min})$

$$
=\frac{\text { VLDL-TG Ra }(\mu \mathrm{mol} / \mathrm{min})}{\text { VLDL-TG concentration }(\mu \mathrm{mol} / \mathrm{ml})}
$$

VLDL-TG fatty acid oxidation - primed-constant infusion:

Fractional oxidation of the infused $\left[1-{ }^{14} \mathrm{C}\right] \mathrm{VLDL}-\mathrm{TG}$ was calculated as follows:

$\frac{\text { Fractional VLDL-TG oxidation }={ }^{14} \mathrm{CO}_{2} \mathrm{SA} \times \mathrm{VCO}_{2}}{k \times \mathrm{Ar} \times \mathrm{F}}$

Here, $k$ is the volume of $\mathrm{CO}_{2}$ at $20^{\circ} \mathrm{C}$ and $1 \mathrm{~atm}$. pressure $(22.4 \mathrm{l} / \mathrm{mol})$, and $\mathrm{Ar}$ is the fractional acetate carbon recovery factor in breath $\mathrm{CO}_{2}$, and $F$ is the tracer infusion rate. Sidossis et al. (13) has previously calculated Ar to be 0.56 for resting conditions. The total VLDL-TG oxidation rate $(\mu \mathrm{mol} / \mathrm{min})$ was 
calculated as follows:

VLDL-TG oxidation rate

$=$ fractional VLDL-TG oxidation $\times$ VLDL-TG Ra

\section{Statistical analysis}

Results were expressed as mean \pm s.D. (parametric data) unless otherwise specified. Statistical comparisons between study days were assessed by paired $t$-test or Wilcoxon's test. $P<0.05$ was considered significant.

Sample size was determined as follows: based on our volunteers body composition, presumed VLDL-TG levels, and previous studies done in our lab, we considered average basal VLDL-TG production rates of $50 \mu \mathrm{mol} / \mathrm{min}$ with s.D. $10 \mu \mathrm{mol} / \mathrm{min}$ realistic. Risk of type I and II errors ( $\alpha$ and $\beta$ ) was set at $5 \%$ giving us a power of $95 \%$. Earlier studies have indicated that VLDL-TG production rates may be augmented by 32-40\% by month-long estrogen administration $(14,15)$. We therefore estimated differences between study days to be $\sim 25 \%$ or $12.5 \mu \mathrm{mol} / \mathrm{min}$. Sample size can then be calculated as $n=(\mathrm{C} 2 \alpha+\mathrm{C} \beta)^{2} \times$ s.D. $^{2} / \Delta^{2}$, where $\mathrm{C} 2 \alpha=$ constant for type I error (two-sided), $C \beta=$ constant for type II error (power $95 \%$ ), and $\Delta=$ estimated difference. In our case, this gives $n=(1.96+1.645)^{2} \times(10)^{2} / 12.5^{2}-$ eight subjects.

\section{Results}

\section{Circulating hormones and metabolites}

By design, all participants had $\mathrm{E}_{2}$ concentrations below detection threshold on the placebo study day, while administration of $4 \mathrm{mg} \mathrm{E}_{2}$ resulted in an increase to premenopausal levels ((placebo versus $\left.\mathrm{E}_{2}\right) \mathrm{E}_{2}(\mathrm{nM})$ : $0.07 \pm 0.01$ vs $0.25 \pm 0.04, P<0.001)$ by the end of the study period. $\mathrm{E}_{2}$ treatment tended to lower circulating FFA, although not statistically significant (FFA (mM): $0.61 \pm 0.13$ vs $0.52 \pm 0.14, P=0.25)$. Total TG concentrations were comparable (TG (mM): 1.22 \pm 0.59 vs $1.10 \pm 0.33, P=0.48)$.

\section{Lipid and glucose oxidation}

Lipid oxidation tended to decrease during $\mathrm{E}_{2}$ treatment (lipid oxidation $(\mathrm{mg} / \mathrm{kg}$ per $\mathrm{min})$ : $0.66 \pm 0.32$ vs 0.47 $\pm 0.08, P=0.12)$; in contrast, glucose oxidation increased significantly (glucose oxidation $(\mathrm{mg} / \mathrm{kg}$ per min): $1.02 \pm 0.20$ vs $1.40 \pm 0.36, P=0.03)$.

\section{VLDL-TG kinetics}

VLDL-TG SA and VLDL-TG concentrations are depicted in Fig. 1A and B. As seen, SA increased tenfold during the primed-continuous infusion, and isotopic steady state was present throughout the sampling period.
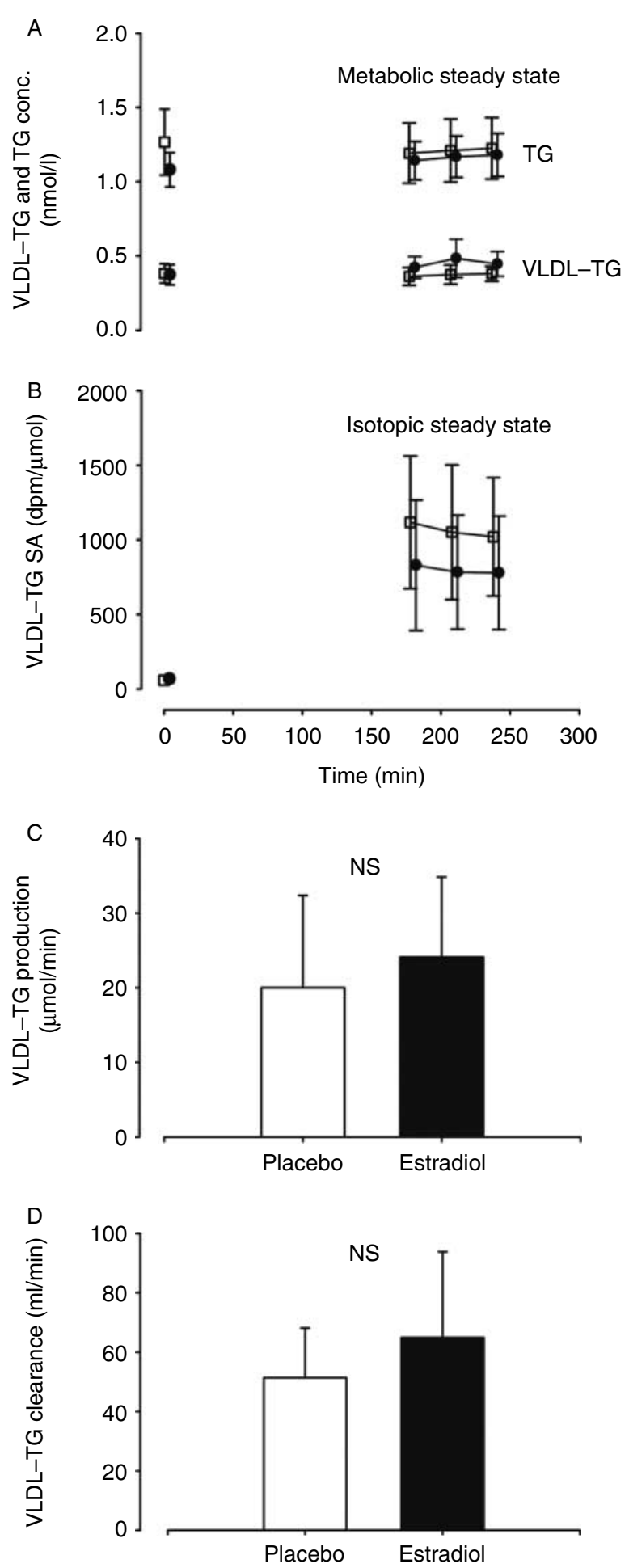

Figure 1 Effects of a single dose of oral estradiol $4 \mathrm{mg}$. (A) Total triglyceride and VLDL-triglyceride concentrations (open square, placebo; solid circle, estradiol). (B) VLDL-triglyceride-specific activity during primed-constant infusion of $\left[1-{ }^{14} \mathrm{C}\right] \mathrm{VLDL}$-triglyceride. Isotopic steady state was obtained during the sampling period ( $t=180-240 \mathrm{~min}$ ). (C) VLDL-TG production rate. (D) VLDLtriglyceride clearance rate. Values are mean \pm S.E.M. 
VLDL-TG production (VLDL-TG production $(\mu \mathrm{mol} / \mathrm{min}): 20.0 \pm 12.4$ vs $24.1 \pm 10.7, P=0.33)$ and clearance rates (VLDL-TG clearance rates $(\mathrm{ml} / \mathrm{min}): 51.4 \pm 16.8$ vs $64.9 \pm 28.8, P=0.34)$ are presented in Fig. 1C and D. No significant difference in VLDL-TG production or clearance rate was observed.

\section{VLDL-TG fractional oxidation}

Fractional VLDL-TG oxidation (Fig. 2B) was not affected by $\mathrm{E}_{2}$ treatment (Fractional VLDL-TG oxidation: 0.57 \pm 0.17 vs $0.53 \pm 0.08, P=0.53)$. Likewise, absolute VLDL-TG oxidation (VLDL-TG oxidation $(\mu \mathrm{mol} / \mathrm{min})$ : $12.3 \pm 10.9$ vs $12.6 \pm 5.6, P=0.93)$ did not differ significantly between study days.

\section{Discussion}

Although long-term estrogen treatment is known to increase plasma TG (2), little is known about the immediate effect on hepatic VLDL-TG production and peripheral clearance. The present study is the first to provide data demonstrating that a single dose of $E_{2}$ (4 mg) does not result in measurable changes in hepatic VLDL-TG production or oxidation in humans.

The high density of ERs on hepatocytes (16) has lead authors to speculate that $E_{2}$ impacts on hepatic VLDL particle formation and secretion. Indeed, animal studies have shown that $\mathrm{E}_{2}$ stimulates hepatocyte VLDL-TG production and secretion $(5,6)$. Moreover, a few human tracer studies have demonstrated that long-term $\mathrm{E}_{2}$ treatment augments hepatic VLDL-TG (14) secretion as well as VLDL apoB secretion (i.e. particle number) (17).

However, there are several points favoring the notion that $\mathrm{E}_{2}$ could augment VLDL-TG production acutely: i) estrogens exert their effects not only via nuclear but also through membrane-bound receptors (7) enabling a rapid intracellular signaling response in the hepatocyte to changes in $\mathrm{E}_{2}$ levels. ii) TG levels fluctuate during the day in healthy humans, and are modified within hours through changes in circulating hormones (e.g. insulin and $\mathrm{GH}$ ) or metabolites (e.g. glucose and FFAs). iii) The increase in $E_{2}$ levels observed during the end of the follicular phase is in some studies (18) mirrored by a concomitant increase in TG levels. The impact of menstrual phase on VLDL-TG kinetics was therefore further explored by Magkos et al. (19), who, contrary to the author's initial hypotheses, found no effect of menstrual phase on VLDL-TG kinetics. However, that particular study was not designed to delineate the independent effects of $E_{2}$ perturbations on VLDL-TG kinetics but rather the combined effects of hormonal changes $\left(\mathrm{E}_{2}\right.$ and progesterone) during the menstrual cycle. Indeed, Wolfe et al. (20) demonstrated that estrogen combined with micronized progesterone administered for 7 weeks does not result in changes in VLDL particle turnover or VLDL-TG concentrations.
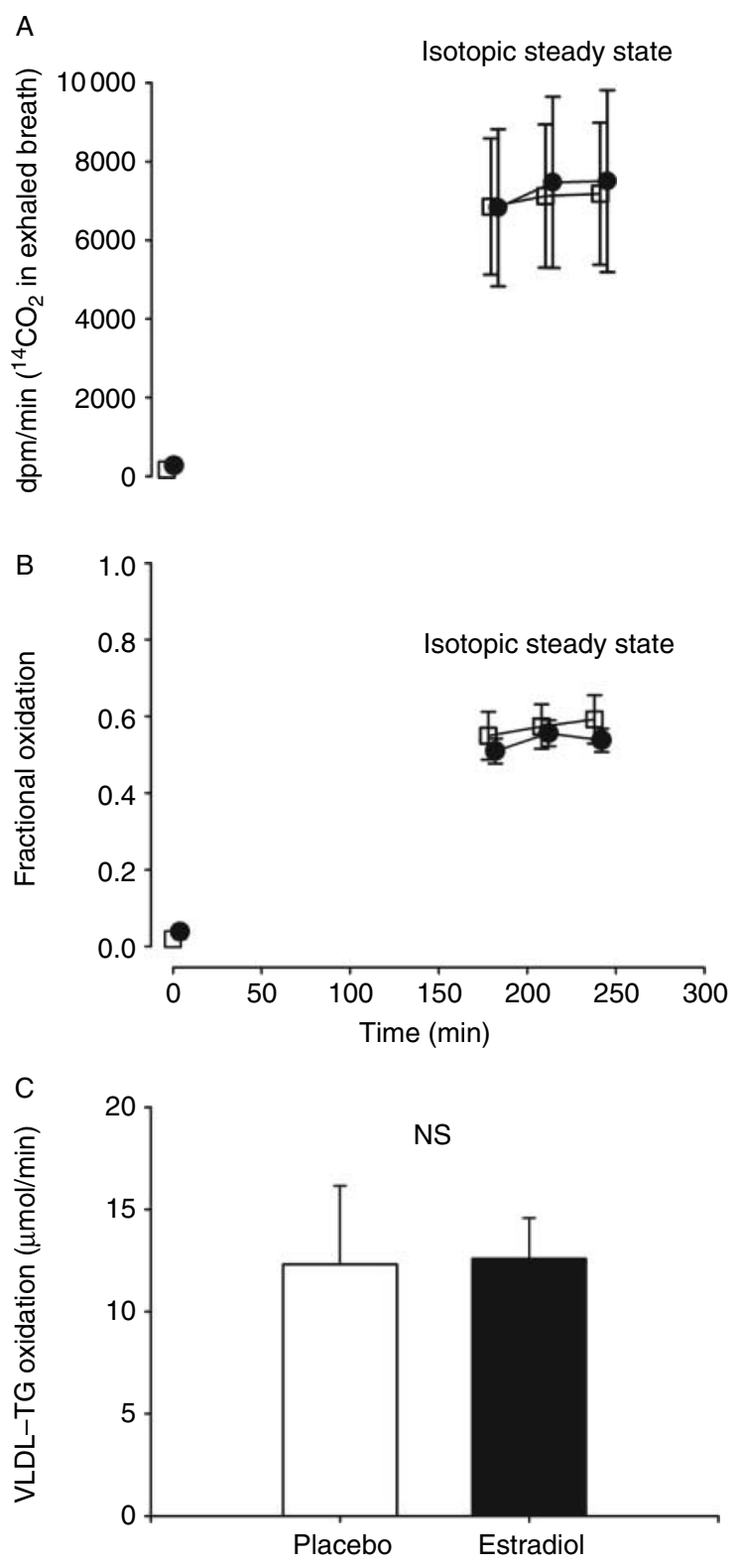

Figure $2(\mathrm{~A})$ Breath $\left[{ }^{14} \mathrm{CO}_{2}\right]$ production rate. Values are derived from measurement of $\left[{ }^{14} \mathrm{CO}_{2}\right]$-specific activity in expired air and $\mathrm{VCO}_{2}$ (indirect calorimetry). Isotopic steady state was reached during the sampling period ( $t=180-240 \mathrm{~min}$ ) (open square, placebo; solid circle, estradiol). (B) Fractional oxidation (\%) of infused VLDL-triglyceride fatty acid tracer. (C) VLDL-TG fatty acid oxidation rate $(\mu \mathrm{mol} / \mathrm{min})$. Values are mean \pm S.E.M.

The present finding of no significant effect of short-term $\mathrm{E}_{2}$ exposure on VLDL-TG production therefore indicates either i) that key enzymes involved in VLDL particle assembly (e.g. microsomal triacylglycerol transfer protein or diacylglycerol transferase) are only up-regulated after long-term exposure, or ii) that substrate availability (circulating FFAs or intrahepatic TG pools) increases after weeks of $E_{2}$ treatment. However, $E_{2}$ has been demonstrated to inhibit lipolysis (21) resulting in 
decreased circulating FFAs (as also observed - albeit not significantly - in this study). It therefore seems plausible that $\mathrm{E}_{2}$ treatment alters hepatic VLDL-TG formation via slow genomic effects on enzymes involved in both VLDL-TG synthesis and VLDL particle formation.

Oral estrogen treatment has been demonstrated to decrease lipid oxidation in a dose-dependent manner in humans (22), and has been shown to reduce ketogenesis (a by-product of hepatic lipid oxidation) in cell culture studies (23). $\mathrm{E}_{2}$ action in the liver therefore likely involves channeling FFAs from oxidative to nonoxidative pathways (primarily VLDL-TG production). We therefore hypothesized that peripheral VLDL-TGs would be diverted in a similar manner away from oxidation and toward storage, i.e. that VLDL-TG oxidation in skeletal muscle would decrease following $\mathrm{E}_{2}$ exposure. Again, our finding of no significant change in VLDL-TG oxidation supports the notion that $\mathrm{E}_{2}$ affects lipid metabolism via slow pathways, both in the liver and in peripheral tissues. We chose a dose of $4 \mathrm{mg}$ of $\mathrm{E}_{2}$ in order to make sure that we would achieve premenopausal circulating levels of serum $\mathrm{E}_{2}$ in the pre-menopausal range, which is often not achieved with lower doses (1-2 mg) of $E_{2}$ often used in the typical postmenopausal setting $(24,25)$. A limitation to the study is the possible type 2 statistical error due to the low number of subjects. Although our power calculation shows that eight subjects in a cross over design is sufficient to detect a statistical difference, our results need to be confirmed in larger studies. Our results cannot be extended to describe the effects of other routes of delivery, e.g. transdermal estrogen. While oral estrogen results in greater concentrations and VLDL-TG particle production (Apo-B100), transdermal estrogen administration results in unchanged or reduced VLDLTG concentrations (26) and unchanged VLDL-TG particle production. The latter finding is, to our knowledge, only reported in one study by Walsh et al. (1). Moreover, we cannot conclude whether short-term treatment (e.g. 1 week) is sufficient to elicit statistical differences in VLDL-kinetics or whether treatment withdrawal results in rapid reversal of such effects. Thus, future studies should address the effect of shortterm treatment and as well as the impact of treatment withdrawal in order to gain a more complete knowledge of the time-dependent changes in VLDL-kinetics. In summary, short-term $\mathrm{E}_{2}$ exposure does not alter VLDLTG production, clearance, or oxidation in healthy postmenopausal women. These data therefore indicate that HRT-associated dyslipidemia has a gradual rather than immediate onset.

\section{Declaration of interest}

L C Gormsen, C Høst, B E Hjerrild, and S Nielsen have no disclosures. $\mathrm{C}$ Gravholt has received lecture fees from Novo Nordisk and Genentech. S Nielsen has received lecture fees from Sanofi-Aventis and MSD.

\section{Funding}

The study was supported by grants (to C Gravholt) from the Danish Medical Research Council (grant number 22-01-0395) and the Novo Nordisk Foundation and from grants (to S Nielsen) from the Danish Medical Research Council (grant number 271-07-0640), the Novo Nordic Foundation, and the Danish Diabetes Foundation.

\section{Acknowledgements}

The authors thank Anette Mengel for excellent technical assistance.

\section{References}

1 Walsh BW, Schiff I, Rosner B, Greenberg L, Ravnikar V \& Sacks FM. Effects of postmenopausal estrogen replacement on the concentrations and metabolism of plasma lipoproteins. New England Journal of Medicine 1991325 1196-1204.

2 Kuller LH. Hormone replacement therapy and risk of cardiovascular disease: implications of the results of the Women's Health Initiative. Arteriosclerosis, Thrombosis, and Vascular Biology 2003 23 11-16.

3 Packard CJ \& Shepherd J. Lipoprotein heterogeneity and apolipoprotein B metabolism. Arteriosclerosis, Thrombosis, and Vascular Biology 199717 3542-3556.

4 Miller KW \& Lane MD. Estradiol-induced alteration of very-lowdensity lipoprotein assembly. Possible competition among apoproteins for incorporation into nascent very-low-density lipoprotein. Journal of Biological Chemistry 1984259 15277-15286.

5 Chan L, Jackson RL, O'Malley BW \& Means AR. Synthesis of very low density lipoproteins in the cockerel. Effects of estrogen. Journal of Clinical Investigation $1976 \mathbf{5 8} 368-379$.

6 Luskey KL, Brown MS \& Goldstein JL. Stimulation of the synthesis of very low density lipoproteins in rooster liver by estradiol. Journal of Biological Chemistry 1974249 5939-5947.

7 Revankar CM, Cimino DF, Sklar LA, Arterburn JB \& Prossnitz ER. A transmembrane intracellular estrogen receptor mediates rapid cell signaling. Science 2005307 1625-1630.

8 Dos Santos EG, Dieudonne MN, Pecquery R, Le Moal V, Giudicelli Y \& Lacasa D. Rapid nongenomic $\mathrm{E}_{2}$ effects on p42/p44 MAPK, activator protein-1, and cAMP response element binding protein in rat white adipocytes. Endocrinology 2002143 930-940.

9 Van Pelt RE, Gozansky WS, Schwartz RS \& Kohrt WM. Intravenous estrogens increase insulin clearance and action in postmenopausal women. American Journal of Physiology. Endocrinology and Metabolism 2003285 E311-E317.

10 Sørensen LP, Gormsen LC \& Nielsen S. VLDL-TG kinetics: a dual isotope study for quantifying VLDL-TG pool size, production rates, and fractional oxidation in humans. American Journal of Physiology. Endocrinology and Metabolism 2009297 E1324-E1330.

11 Gormsen LC, Jensen MD \& Nielsen S. Measuring VLDL-triglyceride turnover in humans using ex vivo-prepared VLDL tracer. Journal of Lipid Research 2006 47 99-106.

12 Ferrannini E. The theoretical bases of indirect calorimetry: a review. Metabolism 198837 287-301.

13 Sidossis LS, Coggan AR, Gastaldelli A \& Wolfe RR. A new correction factor for use in tracer estimations of plasma fatty acid oxidation. American Journal of Physiology. Endocrinology and Metabolism 1995269 E649-E656.

14 Glueck CJ, Fallat RW \& Scheel D. Effects of estrogenic compounds on triglyceride kinetics. Metabolism 197524 537-545.

15 Tikkanen MJ, Kuusi T, Nikkila EA \& Sane T. Very low density lipoprotein triglyceride kinetics during hepatic lipase suppression by estrogen. Studies on the physiological role of hepatic endothelial lipase. FEBS Letters 1985181 160-164.

16 Eisenfeld AJ, Aten R, Weinberger M, Haselbacher G, Halpern K \& Krakoff L. Estrogen receptor in the mammalian liver. Science 1976 $191862-865$. 
17 Campos H, Walsh BW, Judge H \& Sacks FM. Effect of estrogen on very low density lipoprotein and low density lipoprotein subclass metabolism in postmenopausal women. Journal of Clinical Endocrinology and Metabolism 199782 3955-3963.

18 Pahwa MB, Seth S \& Seth RK. Lipid profile in various phases of menstrual cycle and its relationship with percentage plasma volume changes. Clinica Chimica Acta 1998273 201-207.

19 Magkos F, Patterson BW \& Mittendorfer B. No effect of menstrual cycle phase on basal very-low-density lipoprotein triglyceride and apolipoprotein B-100 kinetics. American Journal of Physiology. Endocrinology and Metabolism 2006291 E1243-E1249.

20 Wolfe BM, Barrett PH, Laurier L \& Huff MW. Effects of continuous conjugated estrogen and micronized progesterone therapy upon lipoprotein metabolism in postmenopausal women. Journal of Lipid Research 200041 368-375.

21 Pedersen SB, Kristensen K, Hermann PA, Katzenellenbogen JA \& Richelsen B. Estrogen controls lipolysis by up-regulating $\alpha 2 \mathrm{~A}$ adrenergic receptors directly in human adipose tissue through the estrogen receptor $\alpha$. Implications for the female fat distribution. Journal of Clinical Endocrinology and Metabolism $2004 \mathbf{8 9}$ 1869-1878.
22 O'Sullivan AJ, Hoffman DM \& Ho KK. Estrogen, lipid oxidation, and body fat. New England Journal of Medicine 1995333 669-670.

23 Ockner RK, Lysenko N, Manning JA, Monroe SE \& Burnett DA. Sex steroid modulation of fatty acid utilization and fatty acid binding protein concentration in rat liver. Journal of Clinical Investigation $1980651013-1023$.

24 Ostberg JE, Storry C, Donald AE, Attar MJ, Halcox JP \& Conway GS. A dose-response study of hormone replacement in young hypogonadal women: effects on intima media thickness and metabolism. Clinical Endocrinology 200766 557-564.

25 Gravholt CH, Riis AL, Møller N \& Christiansen JS. Protein metabolism in Turner syndrome and the impact of hormone replacement therapy. Clinical Endocrinology 200767 413-418.

26 Godsland IF. Effects of postmenopausal hormone replacement therapy on lipid, lipoprotein, and apolipoprotein (a) concentrations: analysis of studies published from 1974-2000. Fertility and Sterility 200175 898-915.

Received 8 June 2010

Accepted 21 June 2010 